\title{
CONTRIBUIÇÕES DE FRANZ FANON E PAULO FREIRE PARA A EMERSÃO DE UMA EDUCAÇÃO ANTIRRACISTA
}

\author{
KARINE KOSTUCZENKO \\ DANIELA GHISLENI FIGUEIREDO \\ JOSÉ WNILSON FIGUEIREDO \\ Universidade Federal da Fronteira Sul (UFFS), Erechim, Santa Catarina, Brasil
}

Resumo: O presente trabalho tem como objetivo apresentar reflexões a respeito do racismo em um contexto da presença das diversas formas de colonialismos e colonialidades no mundo, de modo geral, e no Brasil, de maneira particular. Para tanto, vamos nos apoiar nas obras de Fanon e Freire, devido ao fato de que esses autores propõem uma pedagogia aportada numa ética do reconhecimento as todas as alteridades mediante a assunção do acolhimento a todas as pessoas que buscam a superação do racismo de distintas matizes. Ao mesmo tempo, anunciar outro mundo sustentado no diálogo crítico em meio ao reconhecimento das diferenças culturais é nosso intento. A metodologia escolhida neste trabalho é de natureza qualitativa e bibliográfica. A pesquisa propiciou concluir que o diálogo dos ideários de Freire e Fanon é relevante para consecução de uma educação antirracista.

Palavras-chave: Educação. Racismo. Fanon. Freire.

\section{CONSIDERAÇÕES INICIAIS}

O processo de transformação social é o que determina o rumo da democracia, passando por diversas transformações. O reconhecimento dessas transformações, tanto nas questões culturais quanto nas questões políticas e econômicas, está interligado e não se desconecta, sendo, portanto, imprescindível para a construção de um processo que se dá num determinado tempo-espaço de uma sociedade.

Esse processo se constitui por meio dos encontros entre homens e mulheres no, pelo e com o mundo - numa perspectiva que abarca as dimensões políticas e pedagógicas -, as quais são fundamentais para um agir em direção à constituição dos seres humanos como atores sociais inseridos na dinâmica sociocultural de uma comunidade de ensino e de aprendizagem. Comunidade esta que emerge das tramas e das lutas desses homens e mulheres em torno da consecução de relações humanas, que podem ser de dois tipos: de natureza horizontal ou de caráter vertical.

O primeiro tipo, de natureza horizontal, promove um congraçamento ao redor de objetivos e valores calcados em uma ética da reciprocidade em que a cooperação prevalece na estruturação e na organização política e pedagógica do ensino e da aprendizagem, de discentes e docentes, no interior dos espaços escolares formais (as escolas), além de outros espaços não formais das comunidades humanas, as quais são 
permeadas, nesse caso, por um clima amistoso (BUBER; 2001, MOUNIER, 2004).

Esse clima se estabelece pelo descentramento recíproco entre os seres humanos por meio da formação de elos pautados no cuidado com o bem viver de todas as pessoas, cujo eixo central é a efetivação do estreitamento de vínculos sustentados na eminente dignidade do indivíduo como pessoa.

Essa pessoa, que se encontra aberta ao outro e ao mundo, se realiza como um ser comunicativo e solidário a partir da realização de práticas e experiências sociais forjadas em um agir fundado na partilha de ações, palavras e gestos que, em última instância, produza a irrupção do princípio da libertação (DUSSEL, 2012).

Esse princípio emerge por intermédio de uma profusão de relações do tipo eu e tu, cujo ponto de partida e de chegada é a sinergia e a complementaridade entre os polos da relação (eu e tu), os quais se constituem mutuamente, ou seja, o "eu" colabora com o "tu", assim como o "tu" colabora com o "eu", formando, desse modo, um nós comunitário.

Esse "nós" comunitário é formado pelos sujeitos das relações fundadas no princípio eu e tu, que atua no sentido da consecução do diálogo, em meio às diferenças culturais existentes no interior das comunidades humanas, com a finalidade de perpetrar a transformação do mundo do ponto de vista da superação da opressão. Portanto, do surgimento de consensos mínimos aportados na distribuição equitativa dos bens que compõem a vida. Enfim, de consensos mínimos ao redor da criação e recriação de processos políticos e pedagógicos que ensejem um mundo onde não exista oprimidos e nem opressores, mas, sim, um mundo em que todos participem conjuntamente da edificação de um viver conjunto. Desse modo,

\begin{abstract}
O eu dialógico, pelo contrário, sabe que é exatamente o tu que o constitui. Sabe também que, constituído por um tu - um não-eu -, esse tu que o constitui se constitui, por sua vez, como eu, ao ter no seu um tu. Desta forma, o eu e o tu passam a ser, na dialética destas relações constitutivas, dois tu que se fazem dois eu. Não há, portanto, na teoria dialógica da ação, um sujeito que domina pela conquista e um objeto dominado. Em lugar disto, há sujeitos que se encontram para a pronúncia do mundo, para a sua transformação (FREIRE, 2005, p.192).
\end{abstract}

Por outro lado, de modo inverso às relações humanas horizontais, temos a predominância, nos dias de hoje, de relacionamentos estruturados na verticalidade, os quais são caracterizados pela presença da prática do anti-diálogo.

Esse anti-diálogo se organiza sob a égide do princípio eu-isso em que um dos polos dos relacionamentos (o eu) domina o outro polo (o isso), tornando-o objeto. Nesse caso, inaugura-se um modo de existir fundado na ideia de que os seres humanos detentores do poder, que são minoria no mundo, são considerados sujeitos, os quais exercem a opressão às custas dos sofrimentos de uma imensa maioria dos seres humanos, que são reificados (oprimidos) pelos que se designam e se arvoram como sujeitos.

Nesse sentido, o anti-diálogo faz emergir a colonização aniquiladora dos 
oprimidos, no que se refere aos aspectos ontológicos, epistemológicos, políticos e pedagógicos, ao promover a violência física (genocídios) e a violência simbólica (epistemicídios) pela invasão cultural, que se dá por intermédio da "consciência bancária".

Essa consciência é inculcada pelos colonizadores aos colonizados (oprimidos) mediante a utilização de uma educação que valoriza os saberes provenientes das experiências socioculturais dos colonizadores em detrimento das aprendizagens de saberes pertencentes ao universo cultural dos colonizados.

Nesse tipo de educação, prevalece a não criticidade pelo estímulo a um ensino e a uma aprendizagem amorfa e predatória em que apenas o colonizador detém a palavra e, como consequência disso, o colonizado é condenado ao silêncio. Sobre esse tipo de educação praticado no mundo, em especial na América Latina, é possível afirmar que:

\begin{abstract}
As sociedades latino-americanas começam a se inscrever neste processo de aberturas, umas mais que outras, mais a educação ainda permanece vertical. Professor ainda é um ser superior que ensina a ignorantes. Isto forma uma consciência bancaria. $\mathrm{O}$ educando recebe passivamente os conhecimentos, tornando-se um depósito de educador. Educa-se para arquivar o que se deposita. Mas o curioso é que o arquivado é o próprio homem, que perde assim seu poder de criar, se faz menos homem, é uma peça (FREIRE, 1979 , p. 38).
\end{abstract}

Nesse sentido, é necessário superar a "consciência bancária" por meio de uma práxis comunitária forjada por procedimentos teóricos e práticos que promovam a irrupção da consciência crítica de educandos e educadores, a qual se dá pela análise questionadora e profunda dos problemas que se apresentam no mundo do cotidiano das pessoas e nos espaços das instituições sociais.

Essa análise ocorre por intermédio do diálogo entre os discentes e os docentes ao redor da criação e da recriação de saberes constituídos pelas experiências concebidas pela comunhão entre o povo e os intelectuais comprometidos com a transformação social e cognitiva do mundo.

Para que surja essa consciência crítica, é urgente que o tema do racismo seja refletido na teoria e na prática das nossas instituições escolares, devido ao fato de que esse tema foi e é fundante para o desenvolvimento do projeto colonial da modernidade eurocêntrica no período dos últimos quinhentos anos, o qual marcou profundamente as relações humanas e institucionais das sociedades humanas do ponto de vista pedagógico e político.

Essas relações se caracterizaram e se caracterizam pela dominação e subjugação dos colonizados (os oprimidos) por aqueles que detinham e detém o poder (os colonizadores), os quais se utilizaram e se utilizam do racismo para inferiorizar os seres humanos que não atendem a cosmovisão desses colonizadores. Dessa feita, para inferiorizar os colonizados, os colonizadores perpetraram através das instituições socioculturais, sobretudo das universidades, uma educação de viés racista.

Nesse sentido, para contrapor esse tipo de educação, é de fundamental importância que se promovam ações que estimulem o aparecimento de processos 
político-pedagógicos capazes de favorecer a emersão de uma teoria e de uma prática educativa antirracista nos espaços educativos das sociedades humanas, numa perspectiva de como o colonialismo é constituído em associação com o racismo nos espaços das nossas sociedades. Desse modo, ao refletir sobre a questão do racismo, bem como sobre a compreensão acerca da raça em um contexto colonial, ao tratar da natureza do colonialismo, afirma-se que "o sistema colonial é um mundo em compartimentos, dividido em dois, maniqueísta" (FANON, 2009, p.32).

$\mathrm{O}$ autor aludido reflete que o colonialismo é um sistema dualista que divide o mundo em duas categorias de seres humanos: os colonizadores são vistos como portadores do bem e da sabedoria; enquanto os colonizados são portadores do mal e não são considerados como humanos. Essa divisão maniqueísta é perpetrada através de vários mecanismos violentos, tendo o racismo ocupado um lugar de destaque e que ainda perdura nos dias atuais na irrupção do colonialismo, o qual é: "a violência em estado de natureza e, portanto, não pode ser outra coisa senão diante de uma violência ainda maior" (FANON, 2009, p.54).

Freire (2005) aponta, numa direção convergente à de Fanon, quando este reflete sobre o papel desempenhado pelo oprimido, o qual, segundo a concepção freireana, se vê na sociedade como excluído e, assim, vive à margem dela. Essa exclusão do oprimido é decorrente da violência em estado puro dos opressores em que estes colonizam àqueles ao se colocar numa posição de superioridade econômica, ontológica, epistêmica e política. Decorre daí que se formam relações estruturadas em um antagonismo: os superiores (os oprimidos) e os inferiores (os oprimidos). Esse antagonismo gera medo e suspeita por parte dos opressores e revolta por parte dos oprimidos. Como consequência disso, cada movimento desconhecido dos oprimidos, para os opressores, gera um motivo para "colocar o dedo no gatilho" (FANON, 2009, p.64).

A ideia de raça e do racismo, intrinsecamente enraizada em nossa sociedade, traz o reforço da ideia de violência de maneira clara e objetiva sob o viés de colonização. Nessa perspectiva, "a violência assume uma intima relação com a ideia de raça, uma vez que, a partir de tal ideia, em seu aspecto imediato, o mundo colonial passa a ser dividido entre os que pertencem ou não a tal raça" (FANON, 2009, p.34).

A violência, não apenas como modo de ataque ou de defesa, mas entendida como forma de tomada de consciência de sua condição e, portanto, pelo fato de ser e pertencer a algum grupo ou raça faz com que isso seja a providência para um processo de tomada de consciência com relação à sua raça e, a partir dessa conscientização, passar de uma atitude conformista de aceitar os mandamentos oriundos da normatividade dos homens brancos para uma atitude de luta e da propagação dos saberes e experiências sociais e culturais dos subalternos, como, por exemplo, dos negros, dos indígenas, dos asiáticos, dentre outros.

O autor supracitado faz uma reflexão no sentido de que o colonialismo europeu e o racismo são mutuamente constitutivos e, portanto, não podem ser vistos como fenômenos dissociados na realidade social a que estão inseridos os seres humanos, ou seja, a Europa existe porque utilizou a mão de obra daqueles dos quais sofrem até hoje na pele o preconceito de terem construído um império para os outros. 
KOSTUCZENKO, K.; FIGUEIREDO, D. G.; FIGUEIREDO, J. W.

O bem-estar e o progresso da Europa, tão largamente exaltado e manifestado como qualidades essenciais do continente, só puderam ser construídos graças ao suor e os cadáveres dos negros, os árabes, os índios e os amarelos (FANON, 2009, p. 88).

No entanto, mesmo com todo o reforço da superioridade dos colonizadores sobre os colonizados, através da propagação de um racismo de toda a ordem pelo aparato epistemológico e político do projeto da modernidade eurocêntrica, não conseguiram dominar por completo os colonizados, os quais sempre resistiram e resistem à violência perpetrada pelo colonialismo. Assim, pode-se afirmar que "Apesar das incontáveis técnicas para o seu adestramento, os colonizados não podem ser domesticados" (FANON, 2009, p.45-46).

"Para o colonizado, a objetividade sempre é dirigida contra ele" (FANON, 2009, p.69). O fato é que o colonizado não tem apenas o colonizador como seu opressor. Há todo um sistema político hegemônico dominante que "encobre" os colonizados por meio da racialização de corpos e mentes destes e também por intermédio da lógica capitalística individualista e competitiva, que transforma tudo e a todos em interesse mercantil.

Diante desse quadro a que a humanidade atravessa, que é ocasionado pelos mais diversos modos de racismo, tais como os de natureza: epistêmica, da cor da pele, da língua, da religião, da nacionalidade dentre outros, é essencial que se busque a superação desses racismos por meio da denúncia da maneira de ensinar e de aprender sustentada no princípio da hierarquização racial, concomitante com a enunciação de uma proposição de uma educação antirracista com base no ideário freireano e na concepção fanoniana, que, a nosso ver, é e pode se constituir em um dos caminhos, em meio à diversidade de alternativas emancipatórias presente no mundo, para a democratização efetiva dos diferentes espaços pedagógicos e políticos da vida social. Essa democratização se dá pela constituição de práticas que valorizem o aspecto comunitário, cujo núcleo fundante é a valorização do ser humano como essência.

\section{PROPOSIÇÃO DE UMA EDUCAÇÃO ANTIRRACISTA A PARTIR DE FREIRE E FANON}

A transformação social e a busca por igualdade começam a se instaurar com a tomada de consciência sobre si e sobre o meio em que se vive, ou seja, na e com a sociedade em que os seres humanos se inserem e agem como indivíduos competitivos e individualistas ou como indivíduos que se tornam pessoas a partir de práticas educativas estruturadas em ações cooperativas e solidárias com toda a comunidade da vida.

$\mathrm{Na}$ perspectiva de um agir como pessoa, é necessário e imprescindível estabelecer um diálogo e uma reflexão em torno da desigualdade vivida pela maioria dos indivíduos na sociedade capitalista e, desse modo, propor alternativas a esse tipo de sociedade com base na leitura e interpretação da realidade social por meio de um movimento de ação-reflexão-ação.

Nesse sentido, partimos de uma reflexão consciente sobre a opressão promovida pela lógica capitalista da globalização neoliberal vigente e, ao mesmo tempo, vamos intencionar propor caminhos que apontem para uma perspectiva que vai na direção de um entendimento de que o racismo é parte constitutiva e importante das 
opressões quando vista numa ótica do entrelaçamento com outras formas de opressões, tais como: a de classe social, a de gênero, a de etnia, a de sexo, a de nacionalidade, a de religião dentre outras.

Ademais, na perspectiva de divisão entre países centrais, semiperiféricos e periféricos, o cerne do debate é a Europa no sentido de que esse continente reconheça o racismo criado, de modo endógeno, em território europeu, que considera os países que estão localizados na geopolítica do Sul Global como inferiores e, por outro lado, implemente um processo interno de decolonização para que se recupere da desumanidade provocada aos povos da América, da Ásia e da África. Ao se referir à Europa, pode se afirmar que "O que se espera daqueles que os têm mantido por séculos na escravidão, é que os ajudem a reabilitar ao homem, a fazer triunfar ao homem em todas as partes, de uma vez por todas" (FANON, 2009, p.97).

O fenômeno do racismo não é unicamente uma questão relacionada ao aspecto relativo à "cor da pele". Pelo contrário, o racismo se manifesta por diversos marcadores sociais, os quais refletem dimensões epistêmicas, culturais, políticas, econômicas, que inferiorizam os colonizados por meio de uma violência de caráter físico e simbólico.

Essa violência acaba por provocar efeitos danosos aos colonizados pelo fato de que o processo de colonização a que estes são submetidos produzem naqueles um sentimento e uma atitude de desvalia perante a si mesmos. Como decorrência disso, há uma enorme dificuldade para que os colonizados atuem com vistas a se constituir como sujeitos, no e com o mundo, pelo fato de que os colonizadores transmitem comunicados a partir de processos político-pedagógicos que enfatizam que somente os seus conhecimentos são verdadeiros.

Nessa questão atinente ao modo de ser dos colonizados, sobretudo para os habitantes de origem africana, Fanon (2008) medita ao expressar que para o negro tudo é mais difícil, transcendendo a estrutura do ser, porém questiona a questão do pertencer em que se sentem perdidos e deslocados, tendo que se encaixar em alguma cosmovisão, que não seja a sua própria, nos parece que, para o autor aludido anteriormente, nada será capaz de suprir e nem consertar esse passado, algo quase que inimaginável pensado sob o viés de quem nunca precisou se movimentar dentro de culturas sem ninguém respeitar a sua.

Nessa direção, apesar da negação da cultura dos negros, além da introjeção por parte destes da cultura dos colonizadores, há sempre uma resistência e um esforço para reafirmar a presença e o valor da cultura negra no mundo por parte dos movimentos antirracistas.

\footnotetext{
Mas não esqueço que ele possui uma língua própria, um país, e que talvez seja advogado ou engenheiro em sua cultura. Em todo o caso, ele é estranho a meu grupo, e suas normas devem ser diferentes. No caso do negro, nada é parecido. Ele não tem cultura, não tem civilização, nem 'um longo passado histórico'. Provavelmente aqui está a origem dos esforços dos negros contemporâneos em provar ao mundo branco, custe o que custar, a existência de uma civilização negra (FANON, 2008, p. 46).
} 
KOSTUCZENKO, K.; FIGUEIREDO, D. G.; FIGUEIREDO, J. W.

Mesmo que existam muitos movimentos negros, que, através de seus esforços, busquem uma igualdade racial, é importante trazer à reflexão o contexto histórico de escravidão, que tirou do negro uma referência civilizatória. Esse contexto é diferente na população branca.

\begin{abstract}
Não podemos negar que, na construção das sociedades, na forma como negros e brancos são vistos e tratados no Brasil, a raça tem uma operacionalidade na cultura e na vida social. Se ela não tivesse esse peso, as particularidades e características físicas não seriam usadas por nós, para identificar quem é negro e quem é branco no Brasil. E mais, não seriam usadas para discriminar e negar direitos e oportunidades aos negros em nosso país (GOMES, 2005, p. 48).
\end{abstract}

Para entender o racismo dentro de uma sociedade moderna, é preciso entendêlo na sua dimensão e na sua estrutura a partir do entendimento de que o racismo foi uma prática ideológica "inventada" e comunicada aos povos invadidos pelos impérios europeus por meio da imposição do cânone da modernidade eurocêntrica, que se baseia na negação dos saberes e das culturas diferentes desse cânone, cujo objetivo primordial foi e é a dominação total desses povos.

Internamente, nesses países que foram dominados pelos europeus, como é o caso do Brasil, há um colonialismo interno evidenciado pelas mais diversas formas em que os grupos majoritários da população, como os negros, são subalternizados pelas elites brancas e mestiças em todos os espaços da sociedade brasileira. Esse colonialismo interno produz uma visão falsa de que não há racismo no Brasil. A esse respeito, pode-se afirmar que:

\begin{abstract}
Os brasileiros imaginam que vivem numa sociedade onde não há discriminação racial. Porém, a linguagem de classe e de cor no Brasil sempre foi usada de modo racializado "naturalizando" desigualdades que poderiam comprometer uma imagem do país como uma democracia racial (GUIMARÃES, 1995, p.26).
\end{abstract}

No caso do Brasil, há um negacionismo do racismo inconsciente por parte de uma fração da população e um negacionismo consciente por parte das elites para continuar subalternizando o povo mediante o emprego da prática de racismo, entendida não apenas como a discriminação do homem em particular, mas de uma determinada maneira de existir, em que se insere no conjunto caracterizado como "o da exploração desavergonhada de um grupo de homens por outro que chegou a um estágio de desenvolvimento técnico superior" (LUCAS, 2018, p.26).

A questão desse negacionismo se relaciona fortemente com o legado do projeto Modernidade/Colonialidade, que implantou e continua a implantar nos povos dominados por esse projeto. Abaixo, trazemos uma reflexão de uma autora sobre o racismo advindo do paradigma eurocêntrico.

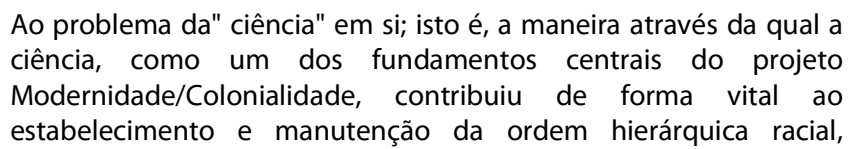


histórica e atual, na qual os brancos e especialmente os homens brancos europeus permanecem como superiores (WALSH, 2007, p. 9).

Em outra perspectiva, que se diferencia da denúncia de Catherine Walsh a respeito do projeto moderno e colonial, o qual assegura a superioridade dos homens brancos europeus, a citação a seguir expressa a comunhão do autor referido com o povo africano, no que diz respeito ao reconhecimento da alteridade desse povo e, por conseguinte, uma atitude decolonial desse autor em sua maneira de atuar política e pedagogicamente no sentido do estabelecimento de uma relação cognitiva e emocional em favor da libertação.

\footnotetext{
Meu primeiro contato com África não se deu, porém, com a GuinéBissau, mas com a Tanzânia, com a qual me sinto, por vários motivos, estreitamente ligado. Faço esta referência para sublinhar quão importante foi, para mim, pisar pela primeira vez em chão africano e sentir-me nele como quem voltava e não como quem chegava (FREIRE, 1984, p. 13-14).
}

Sendo assim, em ambas perspectivas, as questões ligadas à denúncia do projeto da modernidade e os aspectos relacionados ao anúncio de um projeto voltado à consecução de uma utopia concreta em torno da reciprocidade entre a diversidade de epistemes existentes no mundo estão presentes. Essa utopia se dá pela superação da relação entre colonizador e colonizado, por meio da qual se liberta a si e ao colonizador

Ainda, Paulo Freire inspirado em Fanon, ao trazer a ideia de oprimido e opressor, intrinsecamente falando da colonização, além da necessidade de tomada de consciência para que tudo aquilo que fosse exposto seja visto como problema e, sendo problema, exija uma solução, não como uma cura, mas como uma tomada de consciência, "ninguém liberta ninguém, ninguém se liberta sozinho: os homens se libertam em comunhão" (FREIRE, 2005, p.58).

Ou seja, é dada ao oprimido (ao colonizado) a possibilidade de transformação da própria realidade, além de sugerir a educação dialógica como um dos caminhos para essa transformação. Então, pode-se dizer que:

Outro saber de que não posso duvidar um momento sequer na minha prática educativo-crítica é o de que, como experiência especificamente humana, a educação é uma forma de intervenção no mundo. Intervenção que além de conhecimento dos conteúdos bem ou mal ensinados e/ ou aprendidos implica tanto o esforço de reprodução da ideologia dominante quanto 0 seu desmascaramento [...] Neutra, indiferente a qualquer destas hipóteses, a da reprodução da ideologia dominante ou a de sua contestação, a educação jamais foi, é, ou pode ser. É um erro decretá-la como tarefa apenas reprodutora da ideologia dominante como erro é tomá-la como uma força de desocultação da realidade, a atuar livremente, sem obstáculos e duras dificuldades (FREIRE, 
KOSTUCZENKO, K.; FIGUEIREDO, D. G.; FIGUEIREDO, J. W.

2011, p. 96-97).

Por outro lado, de maneira oposta, a educação bancária é um tipo de educação que os colonizadores utilizam para transmitir o racismo epistêmico e outras formas de racismo. Sendo assim, a ideia de racismo como ideologia é algo criado e idealizado pelo colonizador para separar-se e, de alguma forma, tornar-se superior, tornando o negro inferior, como se a ideia de humanidade perpassasse pela ideia de "cor", de forma subjetiva, pela ideia de superiores e inferiores;

Para eles, a "incultura do povo é tal 'que lhes' parece um absurdo falar da necessidade de respeitar a "visão do mundo" que ele esteja tendo. Visão do mundo têm apenas os profissionais" ... Da mesma forma, absurda lhes parece a afirmação de que é indispensável ouvir o povo para a organização do conteúdo programático da ação educativa. É que, para eles, "a ignorância absoluta" do povo não Ihe permite outra coisa senão receber os seus ensinamentos. Quando, porém, os invadidos, em certo momento de sua experiência existencial, começam, desta ou daquela forma, a recusar a invasão a que, em outro momento, se poderiam haver adaptado, para justificar o seu fracasso, falam na "inferioridade" dos invadidos, porque "preguiçosos", porque "doentes", porque "mal-agradecidos" e às vezes, também, porque "mestiços" (FREIRE, 2005, p.177-178).

Freire (2005) ainda enfatiza que o mundo é mundo, sob a ótica da consciência, somos humanidade consciente em sermos humanidade. Dessa feita, a tomada de consciência sobre como se faz uma leitura e compreensão da complexidade da estrutura e da organização da realidade histórica, do mundo da vida e do mundo das instituições socioculturais, exige um esforço de captar essa complexidade. Esse esforço, em nossa ótica, se dá através da implementação de metodologias aportadas na teoria dialógica. Essa teoria se opõe, obviamente, à teoria antidialógica. Assim, pode-se dizer que:

Se, na teoria antidialógica da ação, se impõe aos dominadores, necessariamente, a divisão dos oprimidos com que, mais facilmente, se mantém a opressão, na teoria dialógica, pelo contrário, a liderança se obriga ao esforço incansável da união dos oprimidos entre si, e deles com ela, para a libertação (FREIRE, 2005, p.198).

A transformação da sociedade começa no entendimento e na tomada de consciência do oprimido a respeito dos males produzidos pela opressão praticada pelos opressores. Dessa feita, Freire e Fanon propõem o desvelamento dessa realidade opressora por meio de uma práxis comunitária em que a cooperação e a participação são os eixos propulsores para o desenvolvimento de uma educação de caráter antirracista consignada na decolonização curricular, a qual se faz por meio da denúncia do racismo concomitante com o anuncio de práticas pedagógicas e políticas ensejadas em mandamentos em favor do usufruto de uma vida plena para todos os seres humanos, a qual é vivida a partir da compaixão e da solidariedade com toda a comunidade da vida. 
Nessa direção, é fundamental e imprescindível que se implemente a decolonização dos currículos escolares por meio da introdução de autores e autoras do Sul Global e da periferia da Europa, como são os casos, em nossa visão dos autores ligados à perspectiva decolonial: Boaventura de Sousa Santos, Enrique Dussel, Grosfoguel, Nelson Maldonado Torres, Houria boultedja, Catherine Walsh, Anibal Quijano, Bell Hooks, Angela Davis, Abdias Nascimento, dentre outros, que proponham, em suas obras e em suas práticas de vida, metodologias pedagógicas e políticas para a superação do racismo, como são os casos dos pensamentos e das práticas de Fanon e de Freire.

Para tanto, é necessário que se institua uma formação político-pedagógica de educadores e educandos com base em um paradigma de matiz decolonial, o qual se consubstancia no encontro das diversas epistemes existentes no mundo, que, em última instância, tem como fundamento primeiro a ética do ser mais com o outro, que acontece pela prática da solidariedade e pela cooperação entre todos os seres humanos. A esse respeito, afirma-se que:

\begin{abstract}
Sem dúvida, ninguém pode buscar na exclusividade individualmente. Esta busca solitária poderia traduzir-se em um ter mais, que é uma forma de ser menos. Esta busca deve ser feita com os outros seres que também procuram ser mais e em comunhão com outras consciências, caso contrário se faria de umas consciências, objetos de outras. Seria "coisificar" as consciências. Jaspers disse: "eu sou na medida em que os outros também são". O homem não é uma ilha. É comunicação. Logo, há uma estreita relação entre comunhão e busca (FREIRE, 1979, p.28).
\end{abstract}

Assim, para irromper uma educação antirracista, é preciso promover a unidade construída em torno do diálogo entre saberes com potencial emancipatório das distintas epistemes presentes em meio às diferenças das experiências sociais e culturais de todos os povos existentes no mundo com vistas à edificação de sociedades humanas mais fraternas e compassivas com as diferenças culturais.

Nessa direção, para a implementação de uma educação antirracista nas nossas instituições educativas no Brasil, é urgente que se (re)construam os nossos currículos com vistas a ensejar práticas político-pedagógicas com base num projeto ético e político que vá além do projeto da modernidade eurocêntrica.

Esse projeto parte dos anseios e das experiências sociais e culturais dos oprimidos, "os condenados da terra" e os "esfarrapados do mundo", expressões cunhadas por Fanon e Paulo Freire em diálogo com o fazer político e pedagógico dos ativistas sociais e intelectuais comprometidos com o projeto de implantação de currículos decolonizadores (currículos de características: antirracistas, anticapitalistas, não patriarcais, não cristianocêntricos e não sexistas).

Esse diálogo é e deve ser implementado pela intercomunicação entre as multiplicidades de epistemes que existem entre os distintos lugares do Sul Global, bem como entre esses lugares com as perspectivas críticas do Norte Global, que comungam com as concepções epistemológicas e políticas do Sul Global, como são os casos das 
KOSTUCZENKO, K.; FIGUEIREDO, D. G.; FIGUEIREDO, J. W.

concepções de Boaventura de Sousa Santos e Houria Boltedja.

A respeito desse projeto que vai além da modernidade, pode-se expressar por uma proposta filosófica que vai

em direção a uma futura filosofia global plural. Este projeto é necessariamente transmoderno e, então, também transcapitalista [...]. Por um longo tempo, talvez séculos, as muitas tradições filosóficas seguiram seus caminhos, mas nenhuma delas se parecia com a pluralidade transmoderna (diferente do universal, e não pósmoderno) que aparece no horizonte. Agora, "outras filosofias" são possíveis, pois um "novo mundo" é possível, conforme proclamado pelo Movimento de Libertação Zapatista, em Chiapas, no México (DUSSEL, 2008b, p.20).

Enfim, um projeto que comunga com os ideários freireanos e fanonianos em favor da libertação de todos os povos, a qual se dá pela construção de um mundo possível a partir da diversidade de epistemes existentes no mundo, especialmente daquelas que foram "encobertas" pelo projeto da modernidade eurocêntrica. Nesse sentido, a formação de educadores e educandos com base numa perspectiva epistemológica e política antirracista é imprescindível e necessária para a consecução desse projeto e, por conseguinte, para a implantação de currículos decoloniais.

Esses currículos devem necessariamente ser construídos e reconstruídos com base em práticas pedagógicas e políticas baseadas em premissas antirracistas, que são as seguintes:

Reconhece a existência do problema racial na sociedade brasileira; busca permanentemente uma reflexão sobre o racismo e seus derivados no cotidiano escolar; repudia qualquer atitude preconceituosa e discriminatória na sociedade e no espaço escolar e cuida para que as relações interpessoais entre adultos e crianças negros e brancos sejam respeitosas; não despreza a diversidade presente no ambiente escolar: utiliza-a para promover a igualdade, encorajando a participação de todos/as os/as alunos/as; ensina às crianças e aos adolescentes uma história crítica; busca materiais que contribuam para a eliminação do "eurocentrismo" dos currículos escolares e contemplem a diversidade racial, bem como o estudo de "assuntos negros'; pensa em meios e formar de educar para o reconhecimento positivo da diversidade racial; elabora ações que possibilitem o fortalecimento do auto-conceito de alunos e de alunas pertencentes a grupos discriminados (CAVALLEIRO, 2001, p.158).

Em síntese, a efetivação prática, na nossa visão, de uma educação antirracista é um caminho de muitas lutas e que necessita de um processo cuidadoso e articulado que faça uma decolonização de nossos currículos mediante a formação continuada de educandos e educadores para que estes compreendam e atuem para a superação do racismo no interior das nossas sociedades. Nesse sentido, as obras e a vida de Paulo Freire e de Fanon, quando postas em diálogo, são excelentes caminhos para essa formação, já que esses autores, juntos com tantos outros autores e autoras ligados a 
uma perspectiva antirracista, como Suely Carneiro, Lélia Gonzales, Guerreiro Ramos, dentre outros, trabalharam para a superação do racismo e de outras iniquidades e mazelas sociais em todo o mundo.

\section{CONSIDERAÇÕES FINAIS}

Dividir as pessoas em categorias relacionados em um binarismo, superioridade e inferioridade promove cada vez mais a segregação, não apenas de um indivíduo em especifico, mas de toda humanidade. Utilizar-se de um poder criado ou "inventado" para ter poder sobre outros seres humanos, mais do que negar a humanidade, é distanciar-se do processo de construção humana crítica e cidadã. Somos muito mais do que raça. Somos humanidade.

Romper os padrões sociais relacionados às ideias atinentes ao colonialismo e às colonialidades do ser, do saber, do poder e da natureza, é de fundamental importância para construir um desenvolvimento social e humano pleno e, consequentemente, se desenvolver na sociedade como sujeitos. Enfim, tornar-se sujeito de suas próprias histórias é a essência para a consecução da transformação dos indivíduos como pessoas.

Objetivamente, a construção da igualdade depende do processo de construção, desconstrução e integração crítica, além da ressignificação e a recriação de saberes, dentro de toda a sociedade para almejar, em meio às diferenças culturais, constituir um diálogo intercultural crítico, o qual se dá pelo estabelecimento de interlocuções e práticas em que as assimetria de ideias e concepções não são refutadas e, sim, aprofundadas para se atingir a unidade em meio à profusão de diversidades de epistemes e de políticas existentes no mundo com vistas à consecução da emancipação social e cognitiva de todos os seres humanos.

No atual momento em que o nosso país se encontra, o qual é permeado por um processo de colonização em que o racismo permanece como uma das iniquidades desse processo e que, portanto, atua lado a lados com outras formas de iniquidades (o patriarcalismo, o desemprego, a fome, a miséria dentre outras), é de grande relevância que se desenvolvam processos educativos humanizadores de caráter antirracista.

Desenvolver o caráter humanizador, social e intelectual dos indivíduos, proporcionando a eles mecanismos de escolha e, portanto, proporcionar outras oportunidades, além das impostas, é garantir a continuidade da possibilidade de um futuro de paz e igualdade.

Assim, é preciso que a educação seja um meio para garantir a efetivação da igualdade de raças preconizada na declaração de direitos humanos, ou seja, que a educação promova ações no sentido de proporcionar a superação da classificação preconceituosa com base no critério de raça. Desse modo, remover pela luta esse critério é um grande balizador de ações e estratégias na perspectiva de desenvolver valores, comportamentos éticos com vistas à formação e ao entendimento de que o ser humano é sempre um ser ontologicamente voltado ao ser mais com o outro.

Podemos perceber o quanto a história do continente latino-americano e o mundo estão fortemente marcados por contextos de discriminações e racismos contra os povos subalternizados de modo que todas as categorias de análise aqui 
mencionadas, através dos autores e autoras citados, se inscrevem no objetivo maior que é compreender os processos pelos quais viveram e vivem os colonizados e os colonizadores.

Depreende-se também que toda e qualquer busca por alternativas requer, necessariamente, que seja questionado o conjunto de saberes que foi produzido à custa da imposição de uma ideia de superioridade que, ademais de completamente eurocêntrica, assumiu também características hostis e perversas.

Promover uma reflexão que consiga alcançar o objetivo maior, que é traçar linhas e vertentes que sigam um pensamento humanizador e igualitário, faz-se necessário, e deve caminhar com vistas a processos políticos e pedagógicos emancipatórios em que caibam todas as pessoas.

Por fim, após análise sobre as questões relativas ao racismo, além da opressão produzida pelas diversas formas de racismo, através da leitura de autores e autoras ligados à concepção antirracista, já citados anteriormente neste artigo, verificamos que ainda persiste um falso e forte imaginário da harmonia social presente na sociedade brasileira. Diante desse fato, é preciso que se descontrua esse imaginário por intermédio de uma educação antirracista e dialógica, a qual ajuda na emancipação social dos corpos e mentes das pessoas subalternizadas pela chaga da segregação racial existente no Brasil

Por fim, como conclusão provisória e inacabada, enfatizamos que o campo da educação pode favorecer a transformação social e cognitiva da imensa maioria dos sujeitos discriminados pelos racismos a partir da decolonização dos currículos das nossas universidades e das nossas escolas de ensino básico, bem como de outros espaços pedagógicos da sociedade brasileira.

Essa decolonização pode e dever ser feita a partir do diálogo do entrecruzamento entre autores, autoras e pedagogias ensejadas por esses autores e por essas autoras com vistas à efetivação da prática de processos de ensino e de aprendizagem com base na igualdade em meio ao acolhimento às diferenças. Desse modo, inferimos, a partir desta pesquisa, que o diálogo entre os pensamentos e as práticas de Freire e Fanon é de grande relevância para a consecução de uma educação antirracista nas sociedades humanas, em escala planetária, quando são estudados numa perspectiva da convergência destes com uma multiplicidade de pensadores e pensadoras, que possuem concepções epistemológicas e políticas sustentadas no antirracismo. Para concluir, diríamos que uma educação antirracista, em última instância, deve ser implementada por meio da formação continuada de educandos e educadores com base na construção de currículos que ensejem conteúdos e práticas que evidenciem o reconhecimento e a importância dos indivíduos subalternizados pelas diversas formas de racismos para a construção de um mundo mais humano e solidário.

Artigo recebido em: 14/03/2021

Aprovado para publicação em: 29/06/2021 


\section{CONTRIBUTIONS BY FRANZ FANON AND PAULO FREIRE FOR THE EMERGENCE OF ANTI-RACIST EDUCATION}

ABSTRACT: The present work aims to present reflections on racism in a context of the presence of different forms of colonialism and colonialities in the world, in general, and in Brazil in a particular way. To this end, we will rely on the works of Fanon and Freire, due to the fact that these authors propose a pedagogy based on an ethics of recognition of all alterities by assuming acceptance of all people, which seeks to overcome the wound of racism different nuances and, at the same time, announce another world sustained in critical dialogue amid the recognition of cultural differences. The methodology chosen in this work is of a qualitative and bibliographic nature. The research led to the conclusion that the works of Freire and Fanon are relevant to the achievement of anti-racist education.

KEYWORDS: Education. Racism. Fanon. Freire.

\section{CONTRIBUCIONES DE FRANZ FANON Y PAULO FREIRE PARA LA EMERGENCIA DE LA EDUCACIÓN ANTIRACISTA}

RESUMEN: El presente trabajo tiene como objetivo presentar reflexiones sobre el racismo en un contexto de presencia de diferentes formas de colonialismo y colonialidades en el mundo, en general, y en Brasil de manera particular. Para ello, nos apoyaremos en los trabajos de Fanon y Freire, debido a que estos autores proponen una pedagogía basada en una ética de reconocimiento de todas las alteridades asumiendo la aceptación de todas las personas, que busca superar la herida del racismo diferente. matices $y$, al mismo tiempo, anunciar otro mundo sostenido en un diálogo crítico en medio del reconocimiento de las diferencias culturales. La metodología elegida en este trabajo es de carácter cualitativo y bibliográfico. La investigación llevó a la conclusión de que los trabajos de Freire y Fanon son relevantes para el logro de la educación antirracista.

PALABRAS CLAVE: Educación. Racismo. Fanon. Freire.

\section{REFERÊNCIAS}

BENEVIDES, M. V. de M. Cidadania e Democracia. Lua Nova. Revista de Cultura e Política. São Paulo: CEDEC, n. 33, p. 5-16, 1994.

BUBER, M. Eu e tu. São Paulo: Centauro, 2001.

CAVALLEIRO, E. Educação anti-racista: compromisso indispensável para um mundo melhor. In: CAVALLEIRO, E. (ED). Racismo e anti-racismo na educação: repensando a escola. São Paulo: Selo Negro, 2001. 
KOSTUCZENKO, K.; FIGUEIREDO, D. G.; FIGUEIREDO, J. W.

DUSSEL, E. A New Age in the history of philosophy: the world dialogue between philosophical traditions. Prajñã Vihãra: Journal of Philosophy and Religion, v. 9, n. 1, p. $1-21,2008 b$.

DUSSEL, E. Ética da libertação na idade da globalização e exclusão. Petropólis: vozes, 2012.

FANON, F. Los Condenados de la Tierra. Buenos Aires. $1^{\text {a }}$ Ed. Fondo de Cultura Económica, 2009.

FANON, F. Pele Negra, Máscaras Brancas. Salvador. Editora: EDUFBA, 2008.

FANON, F. Racismo e cultura. In: SANCHES, M. R. (Org.). Malhas que os Impérios tecem. Textos anticoloniais, contextos pós-coloniais. Lisboa: Ed. Lugar da História, 2011.p. 273283.

FREIRE.P. Educação e Mudança. São Paulo: Paz e Terra, 1979.

FREIRE, P. Pedagogia do Oprimido. Rio de Janeiro: Paz e Terra, 2005.

FREIRE, P. Pedagogia da autonomia. 33. ed. Rio de Janeiro: Paz e Terra, 2011.

GOMES, N. L. Alguns termos e conceitos presentes nas relações raciais no Brasil: uma breve discussão. In: SECRETARIA DE EDUCAÇÃO CONTINUADA, ALFABETIZAÇÃO E DIVERSIDADE (SECAD). Educação anti-racista: caminhos abertos pela lei federal $n^{\circ}$ 10.639/03. Brasília: Ministério da Educação, Secretaria de Educação Continuada, Alfabetização e Diversidade (MEC-SECAD), 2005. p. 39-62.

GUIMARÃES, A. S. A. Racismo e anti-racismo no Brasil. Novos Estudos CEBRAP São Paulo, v.43, n.01, nov. 1995.

LUCAS, W. S. J. Representações relacionadas à questão das drogas ilícitas no noticiário de jornais do Rio de Janeiro à luz da teoria de Frantz. 2018. $101 f$. Dissertação (Mestrado em Saúde Pública) - FIOCRUZ, Rio de Janeiro, 2018.

MOUNIER, E. O personalismo. São Paulo: Centauro, 2004.

WALSH, C. Interculturalidad Crítica/Pedagogia decolonial. In: Memórias del Seminário Internacional "Diversidad, Interculturalidad y Construcción de Ciudad", Bogotá: Universidad Pedagógica Nacional, 2007. <Disponível em: https://www.maxwell.vrac.pucrio.br/13582/13582.PDF>. Acesso em: 20 fev. 2021. 
Karine Kostuczenko: Mestranda em Ciências Humanas pelo PPGICH da Universidade Federal da Fronteira Sul - Linha de Pesquisa - Educação, Culturas e Cidadanias Contemporâneas e Graduada em Pedagogia e Acadêmica do Curso de Direito, da Universidade Regional Integrada do Alto Uruguai e das Missões - Campus Erechim.

Orcid: https://orcid.org/0000-0001-6157-652X

E-mail: karinekostuczenko@hotmail.com

Daniela Ghisleni Figueiredo: Graduada em Direito pela Universidade do Contestado (UNC) e Mestranda pelo PPGCIH em Ciências Humanas pela Universidade Federal da Fronteira Sul (UFFS)- Linha de Pesquisa - Educação, Culturas e Cidadanias Contemporâneas.

Orcid: https://orcid.org/0000-0002-3635-7744

E-mail: dany_shisleni@hotmail.com

José WNilson Figueiredo: Professor do Instituto Federal Catarinense - Campus Concórdia; Graduado em Licenciatura plena em Matemática pela Universidade do Vale do Taquari (UNIVATES); Graduado em Asronomia pela Universidade Federal Rural do Semiárido; Mestre em Modelagem Matemática pela Universidade Regional do Noroeste do Estado do Rio Grande do Sul (UNIJUI); Doutor em Educação nas Ciências pela Universidade Regional do Noroeste do Estado do Rio Grande do Sul; Pós-doutor em ensino de Ciências e Matemática pela Universidade Federal do Rio Grande do Norte (UFRN); Pós-doutor em Ciências Humanas pela Universidade Federal da Fronteira Sul (UFFS).

Orcid: https://orcid.org/0000-0002-2461-8724

E-mail: jose.figueiredo@ifc.edu.br

Este periódico utiliza a licença Creative Commons Attribution 3.0, para periódicos de acesso aberto (Open Archives Initiative - OAI). 